\title{
Consanguineous Marriages in Pakistan
}

\author{
Mohammad AfZaL, S. Mubashir Ali and H. B. StYal
}

\section{INTRODUCTION}

In societies where marriage is nearly universal, and the fertility process is almost entirely through marital union, the factors associated with the occurrence of marriage, and through it the reproduction and rearing of children, need to be continuously assessed. Except for prohibited relationships, marriages between close and distant relations, as well as between those not related have been practiced among the muslims. The high incidence of close kin marriages (consanguineous marriages), ${ }^{1}$ including those with first cousins, is a well-known feature of a muslim society. Marriages between close relatives are not only practiced by muslims but also by the people of many other religious affiliations. Within the South Asian subcontinent, besides muslims, christians and other communities, consanguineous marriages have also been practiced by hindus, especially in the south Indian states, and in the central state of Maharashtra. In the northern states of India the prohibition on such marriages is more strictly enforced. ${ }^{2}$ In the south Indian state of Andhra a high proportion of maternal uncle-niece in addition to cross-cousin marriages (especially among maternal cross-cousins) have been in a high propor-

Mohammad Afzal is Joint Director, S. Mubashir Ali and H. B. Siyal are Research Demographers, Pakistan Institute of Development Economies, Islamabad.

Authors' Note: Computer assistance by Mr Masood Ashfaq is thankfully acknowledged.

The word consanguinity literally refers to a relationship based on descent from a common ancestor or a relationship by blood. Consanguineous is a social relationship based on a descent from a common ancestor, either lineal or collateral (that is linked to the same ancestor but not by a direct line of descent). Consanguineous marriage in this paper simply refers to the marriages among such males and females who are related to each other by blood.

${ }^{2}$ According to Sanghvi (1965) "There are three important regulations which largely explain the pattern of marriages in the India. The first one is the regulation of endogamy (marrying within the group of birth) which is the most important attribute of the caste (jati). The second one is the regulation of exogamy (marrying out) which applies to sections in which a caste is divided. It prohibits marriages between individuals who belong to the same section. These sections are usually small in number (15-25 for Brahmins), are known by names (gotra, kul, etc.) and are transmitted in the male line. One of the important consequences of this regulation as far as inbreeding is concerned is to prohibit marriages between children of two brothers, although there would be no bar to marriages between children of two sisters or of brother and a sister. The third one is the regulation of consanguineous (spinda) marriages. It prohibits marriages between two individuals related through a common male ancestor up to 7 th generation and 5th generation on the mother's side". 
tion [Sanghvi (1965)]. For the muslims uncle-niece marriages are not permitted by the Koran.

Although the traditional background of consanguineous marriages among muslims has its roots in the limits defined by the Koran, the occurrence of this phenomenon is also strengthened by the economic and social considerations in society. The study of close kin marriages is not only important to find out the prevalence of consanguineous marriages as such but also to look at its consequences in terms of the differentials (between the so-called inbreeder and outbreeders) in fertility and child morbidity and mortality.

\section{MAIN OBJECTIVES OF THE STUDY}

Data regarding the occurrence of marriages among close relatives including cousins, as well as between non-relatives, were collected from 6611 ever married women, as a part of the 1990-91 Pakistan Demographic and Health Survey [NIPS/IRD Macro (1992)]. The survey has provided a statistical basis for this study to assess the prevalence of consanguineous marriages, and the differentials by age at marriage, fertility and child morbidity and mortality experiences of the women who were married to their cousins and others. The patterns of age at marriage, fertility and proportions of children dead, by urban/rural, will help to assess the validity of the often cited hypothesis that risks to child health due to genetic reasons, are higher among the children of the parents with close blood relations.

\section{FINDINGS OF THE STUDY}

According to the 1990-91 Pakistan Demographic and Health Survey more than half of the ever married women (aged 15 to 49 years) in the selected national sample, were married to their first cousins, (about 50 percent more with the cousins from the father's side than from the mother's side). Including second cousins, the percentage of consanguineous marriages increases from 50.3 to 61.2. Another 1.3 percent were married within the other relations, and the rest, more than 37 percent, were married to non-relatives. The findings of some other studies also confirm that in arranging marriages the preference is given to close kin, but significant proportions are married to non-relatives. ${ }^{3}$

${ }^{3}$ An interesting detailed description on the preferences, arrangements and considerations about the important social function of marriage in a rural Punjabi setup is given in an anthropological study by Elger (1960). Over the last more than three decades, since the study was conducted, many consideration about marriage, especially in the urban segments of the society, may have changed. But the 1990-91 PDHS results have shown that the proportion of marriages arranged within the close relatives, remains very high. 
The proportions of those married to close relatives by current age of the women, show that the pattern of their higher incidence continues among the older and the younger generations. In fact the data show higher percentage of first cousin marriages for those in the younger ages in comparison to those in the upper age groups. This pattern is, however, not evident for those married to second cousins or to other relatives. The 1990-91 PDH Survey further showed that compared to the women who married at relatively younger ages (less than 18) the percentage of those married to first cousins was slightly lower among those who married at higher ages.

The proportion marrying cousins and other relatives in Pakistan is higher in comparison to some other muslim countries of North Africa. For example the estimated percentages of marriages between close relatives based on data collected from the respective Demographic and Health Surveys (1989) carried out in Tunisia, Egypt and Morocco, are 58, 46.6 and 35 [Bittles (1991)].

The 1990-91 PDHS data shows distinct urban/rural differentials in the proportions reporting consanguineous marriages in Pakistan. The percentage of cousin marriages (both first and second cousins) in the urban areas was 51.3, which by including the proportion of those married to other relatives comes to 53.1 percent. The corresponding percentages for the rural areas were 65.6 and 66.9 respectively. Bittles (1989) has reported similar urban/rural differentials for the three North African countries.

Among the four provinces of Pakistan, Balochistan and Punjab showed higher percentage of first cousin marriages ( 53 and 54.4 respectively) in comparison to Sindh (49.7) and N.W.F.P. (38.8). For those married to second cousins and other relatives the differences are not prominent. The corresponding percentages of those who married within relatives, including first and second cousins are: Balochis$\tan$ 67.9, Punjab 65.3, Sindh 61, and N.W.F.P. 52.2.

The differentials by educational status of the females are more clearly indicated for marriages within first cousins, a higher incidence of such marriages among uneducated and the less educated than among those with higher educational status ( 52.2 with no education, 48.9 with primary education, 43.1 with middle level and 32.5 with secondary level education). For the four educational status categories, those who were married to second cousins $(10.4,14.4,10$ and 10.8 percents, respectively) or to other relatives $(1.4,1.8,1.5$, and 1.3 percents, respectively) such differentials are not evident. ${ }^{5}$

${ }^{4}$ Some discussion in this respect is also provided in Sathar and Ahmed (1992).

The higher incidence of consanguineous marriages for the women with no formal education, and lowest for those with secondary and above education, have also been reported for Tunisia, Egypt and Morocco, and for many of the South and West Asian populations [Bittles (1991)]. 


\section{MEAN AGE AT MARRIAGE}

Although marriage is religiously and socially desirable the age at marriage, besides other factors is also determined by the availability of an appropriate match for young women. Demographically the age at marriage has important implications on the length of marital life and hence fertility. Since marriages are mostly arranged, the high percentage of consanguineous marriages should also imply that the period for mate selection and occurrence of marriage may be lesser for such marriages as compared to other marriages. In Table 1 the estimates of mean age at marriage for women married to cousins and to others are compared to look for the differentials by consanguinity status. A comparison of age at marriage has also been made by educational status categories. ${ }^{6}$

\section{Table 1}

Mean Age at Marriage with Spouse as Cousin or Other, by Educational Status. Pakistan 1990-91 PDHS

\begin{tabular}{lcccc}
\hline $\begin{array}{l}\text { Relation } \\
\text { with the } \\
\text { Spouse }\end{array}$ & Illiterate & $\begin{array}{c}\text { Primary } \\
\text { and Below }\end{array}$ & $\begin{array}{c}\text { Middle } \\
\text { and Above }\end{array}$ & All \\
\hline Cousin & 17.4 & 17.7 & 19.6 & 17.7 \\
Other & 17.9 & 18.1 & 20.1 & 18.3 \\
\hline
\end{tabular}

Table 1 shows that the mean age at marriage where the spouse was cousin of the women, is lower than of those married to others, under each educational status category. The difference between the corresponding estimates for marriages with cousin and with others, though marginal, are consistent.

The effect of educational status in enhancing the mean age at marriage is clearly evident, but the increases are higher for those who were educated to middle or higher levels. The higher age at marriage for the educated females is attributed to delay in marriage because of the time involved in its pursuits, and also because it creates awareness to exercise (directly or indirectly) a choice for a suitable partner. In the relatively more educated urban segments of society, delays in the

6These estimates of age at marriage are based on the replies to a question in this regard asked in the 1990-91 PDHS. The estimate of Singulate Mean Age at Marriage (SMAM) derived from proportions single is 21.7 , which is somewhat higher than these estimates. It may also be mentioned that the estimates of SMAM from different sources in Pakistan has been showing an increasing trend -16.7 in 1961, 19.7 in 1972, 20.2 in 1981 and 21.7 in 1990-91 [Government of Pakistan (1992)]. 
marriage of girls may also be caused because of the pursuit by the boy or his parents for a girl from a rich family who can give more expensive dowry [Kayani and Khan (1992)].

\section{CONSANGUINITY IN MARRIAGES AND INCIDENCE OF DIVORCE/SEPARATION}

In the considerations for arranging marriages the general social (as well as religious) emphasis on the strength of marital bondage is manifested in the fact that the proportion of divorced or separated in Pakistan is very small. According to 1990-91 PDHS the percentage of divorced/separated among the ever married women (aged 15-49) was only 1.3 (0.3 percent divorced and one percent separated).

A description of the percentage of divorced/separated among the women married to their cousin or to others (including those married to other relatives and not-related) is provided in Table 2. The table indicates that the incidence of divorce/separation is very low both in urban and rural segments, but it is slightly higher in rural than in the urban areas. ${ }^{7}$ In general the divorces/separations are

\section{Table 2}

Percentage Divorced/Separated among Ever Married Women, with Spouse as Cousin or Other. Pakistan 1990-91 PDHS

\begin{tabular}{lccc}
\hline \multirow{2}{*}{$\begin{array}{l}\text { Current } \\
\text { Age Group }\end{array}$} & \multicolumn{3}{c}{ Relationship with Spouse } \\
\cline { 2 - 4 } Pakistan & Oousin & Other & All \\
\hline Less than 35 & 1.3 & 2.2 & 1.6 \\
35 and Above & 0.9 & 0.7 & 0.8 \\
All Ages & 1.2 & 1.6 & 1.3 \\
Urban Area & & & \\
Less than 35 & 1.1 & 2.1 & 1.5 \\
35 and Above & 1.0 & 0.7 & 0.9 \\
All Ages & 1.1 & 1.5 & 1.3 \\
& & & \\
Rural Area & & & 1.6 \\
Less than 35 & 1.4 & 2.2 & 0.7 \\
35 and Above & 0.8 & 0.7 & 1.4 \\
All Ages & 1.2 & 1.6 & \\
\hline
\end{tabular}

'Similar urban/rural differentials were indicated by 1975 Pakistan Fertility Survey (PFS), 1981 population census and 1988 Pakistan Demographic Survey (PDS). 
indicated to occur more in the younger ages (less than $\mathbf{3 5}$ years) than in the older ages ( 35 years and above). In the case of rural women the percentages of divorce/ separated among those aged less than 35 years, who were married to cousins, were lower than those married to others (i.e. persons from other relatives or non-relatives). For the urban women only those married to first cousins show lower percentage of divorce/separated. This phenomenon in not evident for those aged 35 years and above. In their case the proportions of divorced/separated are higher for those married to first cousins in the urban sample and those married to second cousins in the rural sample. A possible partial explanation for this could be that some of the women in these categories may have been married at a relatively higher ages and for whatever reason, the disruptions in their nuptial relations could have occurred subsequently. The lower percentage of divorced/separated in the higher age group (35 and above) shows that even in their case the incidence of divorce or separation may have mostly occurred soon after marriage when they were young. Also some older women who were earlier divorced or separated may have subsequently remarried and so they were now reported under the category of married.

\section{CONSANGUINEOUS MARRIAGES AND FERTILITY}

Considering that traditional values continue to influence the nuptiality and reproductive behaviour of Pakistani women, should the higher incidence of consanguineous marriages be considered as symbolic of higher fertility? Some studies in Egypt, Morocco and Sudan have reported a higher Total Fertility Rate (TFR) among the couples who were closely related and a lower one among unrelated couples [Bittles (1991)]. In order to see whether any evidence to this effect exists in Pakistan, a comparative view of fertility and consanguinity in marriages have been described in Table 3. The estimates of fertility have been provided in terms of mean number of children ever born per ever married woman aged 15 to 49 years, and by Total Fertility Rates (TFR) based on data referring to 12 months period. The estimates of mean children ever born are also provided by two age categories, namely 'less than 35 years' and ' 35 years and above'.

For women of all ages (15-49) together, the estimates of mean children ever born do not indicate that the fertility of consanguineously married was higher than that of the other women. Only in the case of urban females the estimates for the two categories are of the same level. In fact for those married to cousins the rural estimates are lower. The table, however, further shows that the estimates (by consanguinity status and by urban/rural status) are at least partially influenced by the mean children born (so far) to those who at the time of the survey were less 
than 35 years of age, having obviously not yet completed their reproductive period. For women aged 35 years and above (which included those who completed their reproductive period and those were nearing that age) a slightly higher cumulative fertility for those married to cousins is reported for urban females. In the case of rural females married to cousins, however, the case is the reverse. In others words, the differentials by consanguinity status for the women in ages 35 years and above are reverse to those aged less than 35 years. Compared to these, the estimates of Total Fertility rates for the ever married women, which reflect their current fertility, are observed to be more consistent and provide some indication of the women married to other than cousins having somewhat lower fertility, both for urban and rural areas.

Table 3

Fertility of Women Ever Married to Cousins and to Others: Pakistan 1990-91 PDH Survey

\begin{tabular}{|c|c|c|c|c|c|c|}
\hline \multirow{2}{*}{$\begin{array}{c}\text { Relationship with } \\
\text { Spouse/Age }\end{array}$} & \multicolumn{3}{|c|}{$\begin{array}{l}\text { Mean Children Ever Born } \\
\text { per Ever Married Women }\end{array}$} & \multicolumn{3}{|c|}{$\begin{array}{c}\text { Total Marital Fertility Rate* } \\
\text { (Ever Married Women) }\end{array}$} \\
\hline & Pakistan & Urban & Rural & Pakistan & Urban & Rural \\
\hline \multicolumn{7}{|c|}{ All Ages (15-49 Years) } \\
\hline Cousin & 3.99 & 4.17 & 3.92 & 7.4 & 7.2 & 7.5 \\
\hline Other & 4.19 & 4.16 & 4.20 & 7.2 & 7.1 & 7.3 \\
\hline All & 4.06 & 4.17 & 4.02 & 7.3 & 7.2 & 7.4 \\
\hline \multicolumn{7}{|l|}{ Less than 35 Years } \\
\hline Cousin & 2.84 & 2.85 & 2.83 & & & \\
\hline Other & 2.86 & 2.98 & 2.78 & & & \\
\hline All & 2.84 & 2.91 & 2.81 & & & \\
\hline \multicolumn{7}{|l|}{35 Years and Above } \\
\hline Cousin & 6.13 & 6.25 & 6.08 & & & \\
\hline Other & 6.18 & 5.90 & 6.35 & & & \\
\hline All & 6.15 & 6.08 & 6.18 & & & \\
\hline
\end{tabular}

*It may kept in view that the Total Ever Married Fertility Rates by definition are higher than the corresponding Total Fertility Rates (TFR). The estimate of TFR for Pakistan, from the same source i.e. the 1990-91 Pakistan Demographic and Health Survey, is 5.2 per woman. This rate is based on births occurred during 12 months preceding the survey.

Even though the observed differentials are marginal yet keeping in view that the fertility levels of the country have begun to decline only in the recent years, even small differentials could be considered to reflect a shift away from the traditional apathy in reproductive behaviour. 


\section{CONSANGUINEOUS MARRIAGES AND MORTALITY/MORBIDITY OF CHILDREN}

In the context of genetics and heredity, marriages between close relatives are considered to carry a higher risk of their offspring being less vigorous or having genetic disorders, than of unrelated parents. However, variations in the degree of awareness and the living environment between the women married to cousins and those to others, may also be affecting the incidence of child mortality and morbidity. In order to see whether any indication of ill effects on health of the children born out of consanguineous marriages exits in Pakistan, two measures for child mortality and one for morbidity among children, have been used from the 1990-91 PDHS data. Unfortunately, no data on the prevalence of disability among children were collected in the survey. Such information could have been more useful to see whether the proportion of children with hereditary disease and malfunctions were higher among the children to consanguineous parents than those born to unrelated parents.

\section{Consanguinity and Child Mortality}

In order to look for the differentials in the mortality of children born to mothers who were married to cousins and those to others, two types of estimates have been provided in Table 4. The first type is the ratio of children dead and children ever born, which reflects the cumulative experience of the ever married women aged 15 to 49 years at the time of the survey. The second type is the ratio of children dead to children born during the last five years, which reflects more recent mortality of children.

Table 4 shows that for all women (aged 15-49), the child mortality rates are higher for women married to cousins than to those married to others, except for more recent mortality (second type) of children born to urban females. The expected differentials in this case are eclipsed by the lower recent child mortality for the women aged 35 years and above, who were married to cousins. This may be due to higher child mortality among such women in the younger ages (less than 35) than those in the older ages ( 35 and over), which is not only indicated for urban but also for rural consanguineously married women. If the child mortality experience in the younger ages of the women currently aged 35 years and above, is considered to have been similar to those who were now in the younger age group (less than 35 ), then the past higher child mortality experience may have made them more careful about their later born children. 
Table 4

Children Dead of Children Ever Born, and Ratio of Children Dead and Children Born during Last Five Years, for Women Married to Cousin, or to Other. Pakistan 1990-91 PDH Survey

Children Dead of Children Children Dead Over Children Ever Born per Ever

Relationship with Married Woman

\begin{tabular}{lccccccc} 
Spouse/Age & Pakistan & Urban & Rural & & Pakistan & Urban & Rural \\
\hline Cousin & & & & & & \\
$<35$ & 0.12 & 0.09 & 0.13 & & 0.08 & 0.06 & 0.09 \\
$35>$ & 0.13 & 0.10 & 0.14 & 0.06 & 0.03 & 0.07 \\
All $(15-49)$ & 0.12 & 0.09 & 0.13 & 0.07 & 0.05 & 0.08
\end{tabular}

\section{Other}

$<35$

35>

0.09

0.07

0.10

0.06

0.05

0.06

All (15-49)

0.11

0.10

0.12

0.07

0.06

0.07

0.07

0.11

0.06

0.05

0.07

\section{Consanguinity and Child Morbidity}

The estimates on incidence of morbidity of children, including fever, diar-. rhea and cough, of women who were married to cousins or others, provided in Table 5 show some interesting results. It is observed from the table that the incidence of child morbidity during the reference period of fifteen days before the survey, was highest for women in the youngest age group (less than 25) and lowest in the highest age group ( 35 years and above). This may be due to the younger women being less experienced about looking after the health of the children, than the more experienced older women. The second interesting finding is that for all the age groups the incidence of morbidity among children of urban women was higher than those of rural women. The urban/rural differentials for child morbidity incidence are in the opposite direction to those of child mortality (Table 4). This may at least partly be due to the differences in living conditions in urban and rural areas. While the better availability of medical facilities and more awareness about utilisation of such facilities among the urban women may be contributing to lower child mortality, the better environmental conditions, access to relatively pure and simple food, and the simpler life style may be some of the factors which may be keeping the rural children less prone to morbidity. Yet another possible reason for lower morbidity among the rural children could be that due to higher infant mortality only the fittest among them could have survived. 
In Table 5 the positive association of consanguinity in marriages with incidence of morbidity is only indicated for the rural women in Pakistan. Even though for all married women (both urban and rural) the differentials are observed in the expected direction, the case for urban women is the reverse, with lower child morbidity incidence for those married to cousins and higher for the others. The reasons for this variation are not clear, and require further investigation, possibly through case studies.

\section{Table 5}

Incidence of Morbidity during 15 Days before Survey among Living Children Born during Last Five Years, for Women Married to Cousin, or to Other in Pakistan. 1990-91 PDH Survey

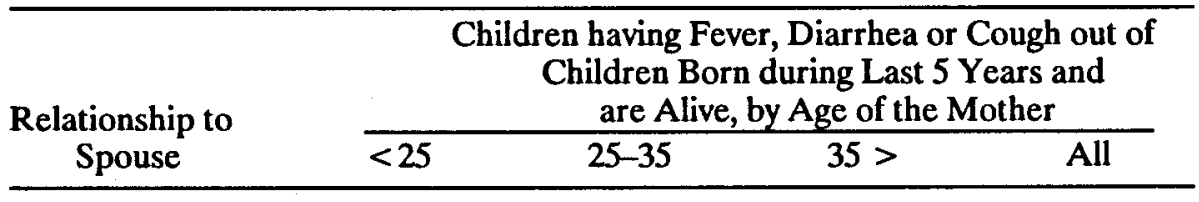

Pakistan

$\begin{array}{lllll}\text { Cousin } & 0.51 & 0.45 & 0.44 & 0.46 \\ \text { Other } & 0.49 & 0.42 & 0.41 & 0.43 \\ \text { All } & 0.50 & 0.44 & 0.43 & 0.45\end{array}$

Urban

$\begin{array}{lllll}\text { Cousin } & 0.52 & 0.47 & 0.46 & 0.48 \\ \text { Other } & 0.57 & 0.49 & 0.49 & 0.51 \\ \text { All } & 0.54 & 0.48 & 0.47 & 0.49\end{array}$

Rural

Cousin

0.51

0.44

0.43

0.46

Other

0.45

0.37

0.38

0.39

All

0.49

0.42

0.41

0.43

\section{SUMMARY AND CONCLUSION}

Like many other countries of Asia and Africa, marriages are almost universal in Pakistan, especially among the females. The high incidence of consanguineous marriages, characterised in Pakistan by marriages between first and second cousins, apart from reflecting the role of traditional values encouraging close kin consideration in the selection of mates through arrangements by the parents, places emphasis on strengthening the conjugal family. Being a predominantly muslim society the 
choice of marriage partners is done by keeping in view the domains defined through Koranic injunctions.

Contrary to the common belief that marriages within close relatives are only practiced by muslims, consanguinity in marriages also exists among hindus, especially is South India. In Pakistan the role of tradition in nuptiality is also reflected by the lower mean age at marriage among the women who are married to their cousins, in comparison to those who are married to others. The role of education in softening the traditional pressure for early marriage of females is clearly manifested by the positive association of educational level with the mean age at marriage. The emphasis of the society on permanence of matrimony and social (as well as religious) undesirability of a marriage break up is clearly manifested by the very small percentages of such happenings in the country, especially among those who were consanguineously married. In terms of reproductive behaviour only marginally higher fertility rates have been observed among those married to cousins than those married to others. This may be due to the decline in fertility levels having begun to occur only in recent years. It was observed that the level of child mortality for those married to cousins has been higher than those married to others, more so for the rural women than for the urban women. In looking for the differentials in the incidence of morbidity by consanguinity status in marriage, the higher child morbidity for those married to cousins, was only observed among rural women, and not by urban women. This finding may imply that the positive association of higher health risks to the children due to consanguinity of the parents or due to other reasons may be more conspicuous in a more traditional rural setup than in the urban segment of the population. The results have, however, shown that with the increase of awareness and experience, which comes as the age of women increases, the incidence of child mortality becomes lower. The role of the environmental factor on the health of the children is reflected by the higher incidence of child morbidity in the urban areas than in the rural areas. Despite the higher incidence of morbidity the existence of better medical facilities and better awareness may have been responsible for keeping the mortality among urban children lower than in the rural areas. Though the results of the study have shown some conspicuous associations of consanguinity in marriages with age at marriage, child morbidity and mortality, but genetic reasons alone cannot be considered to be the factors in bringing about the observed differentials. Certainly the role of socio-economic and environmental factors have been important in the predominant occurrence of consanguineous marriages (and also non-consanguineous marriages) and their consequence on fertility, child mortality and morbidity. The results of 
the study, point toward the need of more in-depth studies on consanguinity in marriages so as to have a better understanding of the factors associated with this important phenomenon.

\section{REFERENCES}

Bittles, Allan H. (1991) Consanguinity: A Major Variable in Studies on North African Reproductive Behaviour, Morbidity and Mortality. Demographic and Health Surveys World Conference. Proceedings Vol. 1. (August 5-7, 1991. Washington, D.C.). Columbia, Maryland: IRD/Macro International, Inc. Kayani, Ashraf K, and Jahangir Khan (1992) Marriage Delays in Pakistan: Analysis of Selected View Points. Pakistan Population Review 3:1.

Mumtaz, Soofia (1979) Divorce: Causes, Process, and Consequences: A Study of Educated Urban Divorcees in Pakistani Society. A Research Report submitted in partial fulfilment of the requirements for the Master's degree in Anthropology, at the Quaid-i-Azam University, Islamabad.

Pakistan, Government of (1992) Women and Men in Pakistan (A Statistical Profile). Islamabad: Federal Bureau of Statistics.

Pakistan, Population Planning Council (1976) Pakistan Fertility Survey. First Report. Islamabad.

Pakistan, NIPS/IRD Macro (1992) Pakistan Demographic and Health Survey 199091. Islamabad. National Institute of Population Studies. Columbia, Maryland: IRD/Macro International Inc.

Sanghvi, L. D. (1965) Inbreeding in India. Papers Contributed by Indian Authors to the World Population Conference Belgrade Yugoslavia 30 August-10 September 1965. New Delhi. Office of the Registrar General India.

Sathar, Zeba, and Tauseef Ahmed (1992) Proximate Determinants of Fertility. Pakistan Demographic and Health Survey 1990-91. Islamabad: National Institute of Population Studies. Columbia, Maryland: IRD/Macro International Inc. 


\section{Comments on}

\section{"Consanguineous Marriages in Pakistan"}

In South and West Asia increasing emphases is being paid to the association of consanguinity with increased fertility and mortality. The demographic characteristics of consanguineous marriages in most studies are considered early age at marriage, rural or extended family set-up and low socio-economic status. Very few studies have controlled for background demographic variables and still fewer have paid attention to the behavioural aspects of consanguinity leading to a paucity of empirical evidence regarding the social, cultural and behavioural dynamics that are at play in such relationships. The problem becomes all the more important for a country like Pakistan where, as reported in this paper by authors, over 60 percent of the marriages are between first or second cousins. High fertility levels, higher rates of infant and child mortality coupled with poverty and low status of women makes it an interesting case study.

There is a need to review briefly the evidence from the literature. The incidence of consanguineous marriages has declined in most of the Western countries. Since the nineteenth century, there has been little or no equivalent changes in the proportion of marriages contracted between close relatives in major population groups throughout North Africa, West and South Asia. This also pertains to some of the newly independent republics of central Asia.

The highest rates of consanguineous marriages have been consistently reported in more traditional rural areas, and amongst the least educated and often poorer sections of the society. But cousin unions are also common in some major landowning families. Thus irrespective of family financial situation the maintenance of the family property is a major determinant of consanguineous marriages and factors such as reduced payment of dowry of bride-wealth are of secondary importance.

Besides the socio-economic considerations consanguineous marriages are also socially acceptable because of the ease of pre-nuptial negotiations. It is widely believed that consanguineous marriages offer optimum opportunity for compatibility between the husband and the wife and the bride and the mother-in-law. Furthermore, there is an important consideration favouring consanguineous marriages and that is the conviction that by marrying within the extended family hidden characteristics regarding health or other unfavourable social characteristics of the 